${ }^{9}$ Taylor, I L, et al, American fournal of Physiology, 1978, 235, E443.

${ }^{10}$ Adrian, T E, et al, Lancet, 1977, 1, 161.

11 Schwartz, T W, et al, Gut, 1978, 19, 982.

12 Hilsted, J, and Jensen, S B, Acta Medica Scandinavica, 1979, 215, 385.

13 Jersild, M, and Lauritzen, E, Diabète, 1957, 6, 237.

14 Trinder, P, Fournal of Clinical Pathology, 1969, 22, 246

15 Floyd, J C, et al, Recent Progress in Hormone Research, 1977, 33, 519.

16 Levitt, N S, et al, Scandinavian fournal of Gastroenterology, 1978, 13, suppl No 49 , p 115.

17 Sundler, F, et al, Cell and Tissue Research, 1977, 178, 307.
18 Gepts, W, and De Mey, J, Diabetes, 1978, 27, suppl No 1, p 251.

19 Gepts, W, De Mey, J, and Marichal-Pipeleers, M, Diabetologia, 1977, 13, 27.

${ }^{20}$ Maher, T D, et al, Diabetes, 1977, 26, 196.

${ }^{21}$ Campbell, L V, Kraegen, E W, and Lazarus, L, British Medical fournal, $1977,2,1527$.

${ }^{22}$ Adrian, T E, et al, Diabetologia, 1978, 14, 413.

${ }^{23}$ Hermansen, K, and Schwartz, T W, Endocrinology. In press.

(Accepted 2 October 1979)

\title{
Iron-deficiency anaemia and its effect on worker productivity and activity patterns
}

\author{
V R EDGERTON， G W GARDNER，Y OHIRA， K A GUNAWARDENA， B SENEWIRATNE
}

British Medical fournal, 1979, 2, 1546-1549

\section{Summary and conclusions}

The effects of iron-deficiency anaemia on worker productivity were studied in a tea plantation in Sri Lanka. The quantity of tea picked per day was studied before and after iron supplementation or placebo treatment. After one month's treatment significantly more tea was picked when the haemoglobin $(\mathbf{H b})$ concentration was increased by iron supplementation than when it was not. The degree of improvement was greater in more-anaemic subjects (those with concentrations of 6.0-9.0 $\mathrm{g} \mathrm{Hb} / \mathrm{dl})$. The level of physical activity of anaemic subjects in their everyday environment was also recorded for four or 24 hours continuously both before and after treatment. After three weeks these levels were significantly greater in the iron-treated than matched placebo-treated subjects.

The economic implications of increased work productivity with iron treatment are evident, particularly in developing countries. These results also provide strong evidence for the clinical impression that people with iron-deficiency anaemia suffer from tiredness and weakness.

\section{Introduction}

Three fundamentally different questions are relevant to the potential biological effects of iron-deficiency anaemia. Firstly, for example, to an athlete the important question is related to maximal performance capacity. Secondly, to the worker whose survival depends on his job performance the daily work productivity is often a crucial factor, particularly in developing

\footnotetext{
Department of Kinesiology, University of California, Los Angeles, California, USA

V R EDGERTON, PHD, professor

$G$ W GARDNER, PHD, professor

Y OHIRA, MS, research assistant

Department of Medicine, University of Sri Lanka, Peradeniya, Sri Lanka

K A GUNAWARDENA, MD, professor

B SENEWIRATNE, MD, professor
}

countries. A third question is related to a person's general sense of wellbeing or vitality, though it remains to be determined whether this is affected by iron-deficiency anaemia. Since the first question has been dealt with fairly completely, we describe here a study conducted to answer the second and third questions. All experimental procedures were carried out according to guidelines on patient care adopted by Kandy General Hospital.

\section{Methods}

The experimental protocol of this study was described fully to each subject and voluntary consent obtained in all cases. The subjects were allowed to withdraw from the study at any time without forfeiting any benefits of the medical screening programme. From an initial screening of haemoglobin $(\mathrm{Hb})$ concentration in 217 female workers, all of whom lived and worked on the same tea estate (Oodawella) in the Kandy area of Sri Lanka, we established two experimental groups. The $\mathrm{Hb}$ concentration was determined by the cyanmethaemoglobin method. Ages of the subjects ranged from 20 to 60 (mean 35.3) years. Because the labour force was divided into four separate divisions based on geographical location on the estate we matched the subjects within divisions according to their initial $\mathrm{Hb}$ concentration and productivity. Productivity was calculated from the average weight of tea picked per day over the previous 12 months. This pairing on the basis of productivity was considered to be necessary to account for differences in skill between subjects and the regional and seasonal differences in tea growth (yield) between divisions. The study was conducted during the drought season. Therefore, overall productivity was steadily declining in all divisions. In the studies of both productivity and voluntary activity two groups were classified as either a control, or placebo, group or a treatment group. The placebo group received a daily tablet of calcium lactate $(300 \mathrm{mg}$ ), while the treatment group received a tablet of ferrous sulphate $(200 \mathrm{mg})$. Tablets were dispensed daily at either the morning or evening "weigh-in," when the weight of the tea the subjects had picked in half a day was measured and recorded. One of us supervised the procedure daily to make sure all subjects received and swallowed the correct tablet. We were not in contact with the subjects apart from giving them the pills.

In the study of productivity we treated 199 subjects for one month with iron or a placebo. Haemoglobin concentrations and tea productivity were screened again one month after treatment began. The placebo group was then given the same iron medication as the treatment group and the study was continued for one more month At the end of the second month $\mathrm{Hb}$ concentrations were again measured in all subjects and production data calculated.

To determine the effects of iron treatment on voluntary activity we studied nine pairs of subjects. The $\mathrm{Hb}$ concentration was monitored before and eight and 19 diys after treatment with iron or placebo was begun. At the end of about three weeks iron treatment for the placebo group was started.

Physical activity was recorded by placing a device about the size of 
a wrist watch $(4.4 \times 3.7 \times 1.8 \mathrm{~cm}$, weighing $77 \mathrm{~g})$ attached to an expandable wrist-watch strap just above the right ankle. The strap was further secured in place with adhesive tape. This sensing device was connected to a tape recorder secured to a belt around the waist. One type of tape recorder weighed $400 \mathrm{~g}$, measured $11.2 \times 8.7 \times 3.6 \mathrm{~cm}$ (Oxford Instrument $\mathrm{Co}$ ), and could record for 24 hours continuously (three pairs of subjects). A second type of recorder weighed $455 \mathrm{~g}$, measured $13.5 \times 7.0 \times 3.4 \mathrm{~cm}$ (Del Mar Engineering Laboratories), and recorded for up to four hours continuously (six pairs). All subjects were asked to proceed with their daily routine as if the recorders were not being worn. The sensing device used for recording physical activity consisted of a weight attached to a spring connected to a piezoelectric crystal. Physical movement caused the spring to move, which was translated into voltage fluctuations varying in amplitude but at a constant frequency determined by the spring. Each subject wore the same recorder and sensor each time. Those subjects who wore the four-hour recorders did so at the same time each day. Each pair of subjects was assigned the same type of recorder, and recordings were made in each pair simultaneously. Moreover, recordings were made in each subject on the same two days of each week. Two recordings were made before any medication was administered. These data served as the baseline.

Activity was assessed at 30-minute intervals and totalled for the four or 24 hours; it was measured by summing the fluctuations in voltage amplitude resulting from the oscillations of the spring device secured above the ankle. These values were compared with the baseline data and with the values obtained in the paired subject. Mean heart rates were obtained for each 30-minute interval and compared with the baseline rate and the rate in the paired subject. Haemoglobin response to treatment was assessed by using a paired $t$ test to compare the values obtained before and each test day after the start of treatment. Percentage changes in daily activity and productivity in the two groups were also compared by using a paired $t$ test.

\section{Results}

Figure 1 shows the variation in the amount of tea picked per day in each division of the tea estate for the 12 months preceding the treatment study. Table I shows the mean $\mathrm{Hb}$ concentration for each

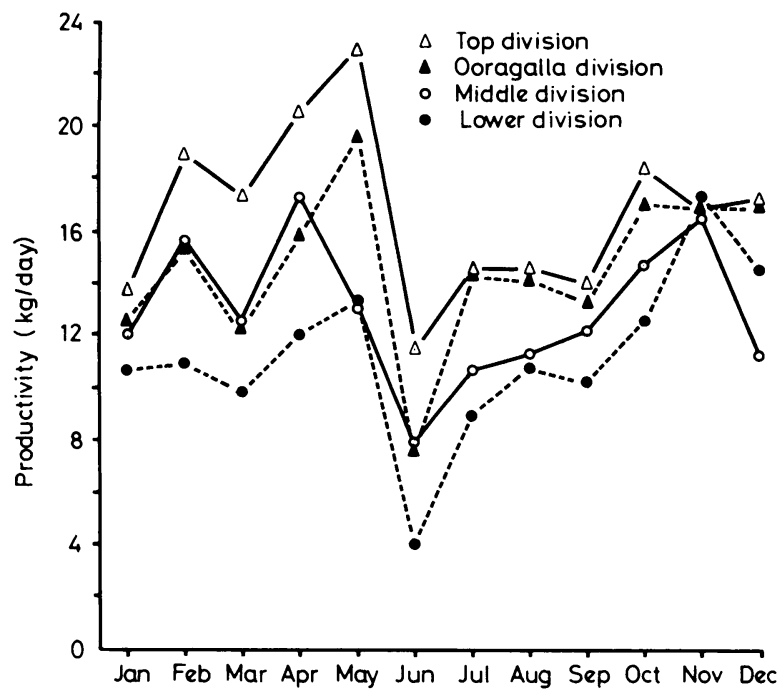

FIG 1-Monthly fluctuation in mean daily productivity (weight of tea picked) in 12 months preceding treatment study.

division before and after iron or placebo treatment. During the second month the concentration in the original treatment group did not increase but a significant increase was observed in each division in the original placebo group. The drop in productivity in three of the four divisions was greater in the placebo than treatment group after one month of treatment and in the fourth (the middle) division was the same (table II). The mean net effect in all four divisions was $+0.2 \mathrm{~kg}$ day. During the second month the newly treated subjects in the placebo group picked more tea $(0.4 \mathrm{~kg}$ /day) than the subjects in the
TABLE I-Mean ( $\pm S E$ of mean) haemoglobin $(\mathrm{Hb})$ concentration $(\mathrm{g} / \mathrm{dl})$ in each of the four working divisions before and after iron treatment

\begin{tabular}{|c|c|c|c|c|c|}
\hline \multirow{2}{*}{ Treatment } & \multicolumn{5}{|c|}{ Concentration } \\
\hline & Initially & $\begin{array}{c}\text { After } \\
\text { 1st month }\end{array}$ & $\begin{array}{l}\text { Change in } \\
\text { 1st month }\end{array}$ & $\begin{array}{c}\text { After } \\
\text { 2nd month }\end{array}$ & $\begin{array}{l}\text { Change in } \\
\text { 2nd month }\end{array}$ \\
\hline \multicolumn{6}{|c|}{ Top division } \\
\hline Placebo & $\begin{array}{c}10 \cdot 2 \pm 0.9 \\
(\mathrm{n}=8)\end{array}$ & $\begin{array}{c}11 \cdot 0 \pm 0 \cdot 9 \\
(n=8)\end{array}$ & +0.8 & $\begin{array}{c}12 \cdot 6 \pm 0 \cdot 7 * \\
(\mathrm{n}=13)\end{array}$ & $+1 \cdot 6 \ddagger$ \\
\hline Iron & $\begin{array}{c}10 \cdot 8 \pm 0 \cdot 6 \\
(\mathrm{n}=14)\end{array}$ & $\begin{array}{c}12 \cdot 8 \pm 0 \cdot 5 * \\
(\mathrm{n}=14)\end{array}$ & $+2.0 \dagger$ & $\begin{array}{c}12 \cdot 5 \pm 0.5 \\
(n=9)\end{array}$ & $-0 \cdot 3$ \\
\hline Net effect & & & $+1 \cdot 2$ & & +1.9 \\
\hline \multicolumn{6}{|c|}{ Ooragalla division } \\
\hline Placebo & $\begin{array}{c}11 \cdot 4 \pm 0.3 \\
(n=33)\end{array}$ & $\begin{array}{c}11 \cdot 5 \pm 0 \cdot 3 \\
(\mathrm{n}=33)\end{array}$ & $+0 \cdot 1$ & $\begin{array}{c}13 \cdot 1 \pm 0 \cdot 2 * \\
(\mathrm{n}=33)\end{array}$ & $+1.6 \ddagger$ \\
\hline Iron & $\begin{array}{c}10 \cdot 7 \pm 0 \cdot 3 \\
(\mathrm{n}=27)\end{array}$ & $\begin{array}{c}12 \cdot 5 \pm 0 \cdot 2 * \\
(\mathrm{n}=27)\end{array}$ & $+1.8 \dagger$ & $\begin{array}{c}13 \cdot 2 \pm 0 \cdot 3 \\
(\mathrm{n}=24)\end{array}$ & +0.7 \\
\hline Net effect & & & $+1 \cdot 7$ & & +0.9 \\
\hline \multicolumn{6}{|c|}{ Middle division } \\
\hline Placebo & $\begin{array}{c}10 \cdot 9 \pm 0 \cdot 3 \\
(\mathrm{n}=33)\end{array}$ & $\begin{array}{c}11 \cdot 6 \pm 0.4 \\
(\mathrm{n}=33)\end{array}$ & +0.7 & $\begin{array}{c}12 \cdot 6 \pm 0 \cdot 3 * \\
(\mathrm{n}=33)\end{array}$ & $+1 \cdot 0 \ddagger$ \\
\hline Iron & $\begin{array}{c}10 \cdot 8 \pm 0 \cdot 2 \\
(\mathrm{n}=45)\end{array}$ & $\begin{array}{c}12 \cdot 8 \pm 0 \cdot 2^{*} \\
(\mathrm{n}=45)\end{array}$ & $+2 \cdot 0 \dagger$ & $\begin{array}{c}12 \cdot 8 \pm 0 \cdot 2 \\
(\mathrm{n}=42)\end{array}$ & 0 \\
\hline Net effect & & & $+1 \cdot 3$ & & $+1 \cdot 0$ \\
\hline \multicolumn{6}{|c|}{ Lower division } \\
\hline Placebo & $\begin{array}{c}11 \cdot 3 \pm 0.4 \\
(n=22)\end{array}$ & $\begin{array}{c}11 \cdot 3 \pm 0 \cdot 4 \\
(\mathrm{n}=22)\end{array}$ & 0 & $\begin{array}{c}12 \cdot 9 \pm 0.3^{*} \\
(\mathrm{n}=22)\end{array}$ & $+1 \cdot 6 \ddagger$ \\
\hline Iron & $\begin{array}{c}10 \cdot 7 \pm 0 \cdot 3 \\
(\mathrm{n}=17)\end{array}$ & $\begin{array}{c}12 \cdot 5 \pm 0 \cdot 2^{*} \\
(\mathrm{n}=17)\end{array}$ & $+1 \cdot 8+$ & $\begin{array}{c}12 \cdot 8 \pm 0 \cdot 2 \\
(n=16)\end{array}$ & +0.3 \\
\hline Net effect & & & $+1 \cdot 8$ & & $+1 \cdot 3$ \\
\hline Mean net effect & & & +1.5 & & $+1 \cdot 3$ \\
\hline
\end{tabular}

Net effects represent effects of iron after one month $\dagger$ compared with placebo and Net efrects represent effects of iron after one month $\uparrow$ compared with placebo and originally receiving iron.

Significance of difference between values obtained before and one month after iron treatment: ${ }^{*} \mathrm{P}<0.05$ (paired $t$ test)

original treatment group. When the treatment effects of the first and second months were combined the improvement in productivity was significant $(P<0.05)$.

Other observations also suggested that $\mathrm{Hb}$ concentration affects work productivity. For example, the average weight of tea picked per day during the 12 months before this study by subjects with a pretreatment $\mathrm{Hb}$ concentration of less than $9.0 \mathrm{~g} / \mathrm{dl}$ was $15.6 \mathrm{~kg}$ compared with $16.2 \mathrm{~kg}$ for those with a pretreatment concentration $\geqslant 11.0 \mathrm{~g} / \mathrm{dl}$ $(\mathrm{P}<0.01)$. Furthermore, in those subjects in whom the concentration was under $9.0 \mathrm{~g} / \mathrm{dl}$ initially $(\mathrm{n}=29$, mean concentration $7.8 \mathrm{~g} / \mathrm{dl})$ the mean concentration one month after iron treatment was $11.5 \mathrm{~g} / \mathrm{dl}$ $(P<0.001)$. In 32 subjects, who included the above 29 , the amount of tea picked increased from $15.6 \mathrm{~kg}$ /day initially to $17.5 \mathrm{~kg}$ /day one month after iron treatment, or by $12 \%(\mathrm{P}<0.01)$. This represents an increase of about $0.75 \mathrm{~kg}$ of tea/day $/ \mathrm{g} \mathrm{Hb} / \mathrm{dl}$ blood.

Figure 2 shows typical recordings of physical activity and heart rate in one subject over 24 hours. Both activity and heart rate were much increased during the daylight hours. Figure 3 (top) shows that the subjects who received the iron tablets were significantly more active two and three weeks after the start of treatment than their matched pairs who received a placebo, although there was no significant difference for the first two weeks. At one week $\mathrm{Hb}$ concentration had risen to $9 \cdot 8 \div 0 \cdot 6 \mathrm{~g} / \mathrm{dl}$ (fig 3, bottom). Between eight and 19 days a small but significant rise in concentration occurred in the placebo group. The

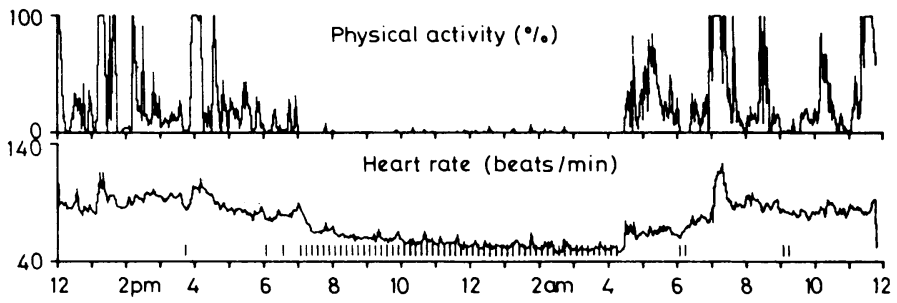

FIG 2-Recordings of physical activity and heart rate obtained from 24-hour recorders in one subject. Physical activity is expressed as a percentage of the maximal activity recorded for the subject in each recording session. Vertical lines in heart-rate recording show points at which trends were adjusted. 
amount of tea picked daily was not affected significantly within the three weeks that these subjects were studied.

In two of the three pairs of subjects who wore the 24-hour recorders the mean heart rate at a given activity level was clearly lower in the subject who received iron compared with the control subject $(56 \%)$. This effect persisted from the third to the last day of the study. The difference did seem to become greater with time. In the third pair the ratio of heart rate to activity did not change with treatment.
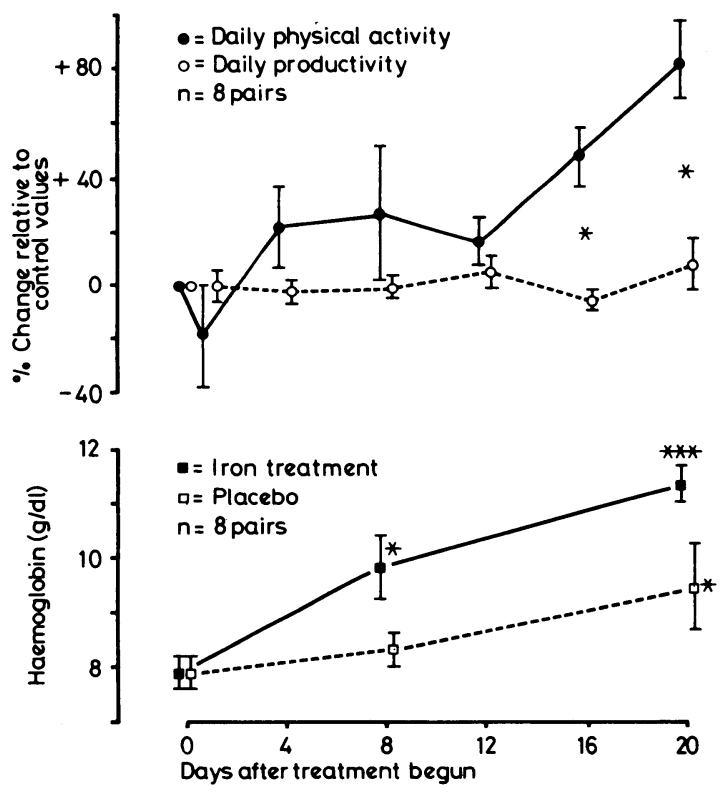

FIG 3-Top. Percentage changes (mean $\pm S E$ of mean) in daily physical activity and productivity (amount of tea picked) in response to oral iron treatment compared with pretreatment control recordings in eight pairs of subjects. Significance of difference between activity before and each day after start of treatment: ${ }^{*} \mathrm{P}<0.05$ (paired $t$ test).

Bottom. Changes in haemoglobin concentrations (mean \pm $S E$ of mean) in response to iron or placebo treatment. Significance of difference: ${ }^{*} \mathrm{P}<0.05,{ }^{* * *} \mathrm{P}<0.001$.

\section{Discussion}

The effects of some nutritional factors on work productivity have been studied. ${ }^{1-3}$ In this study, as in the study of latex workers by Basta and Churchill, ${ }^{1}$ we could correlate the results of the work performed with the degree of anaemia. The data reported here support the concept that work productivity may be improved in subjects with moderate iron-deficiency anaemia treated with iron. The overall mean increase in tea picked per day that could be attributed to iron treatment was $0.3 \mathrm{~kg}$. This increase is impressive considering that the mean $\mathrm{Hb}$ concentration in all the subjects was $11 \mathrm{~g} / \mathrm{dl}$. The subjects with lower $\mathrm{Hb}$ concentrations initially seem to have experienced the greatest increase in productivity.

The validity of expressing the tea picked by the treatment group relative to the placebo group in the first month and by the placebo group relative to the treatment group in the second month, when both groups were receiving iron, may be questioned. The data in table II, however, as shown by divisions and by month, support our conclusion that an increased $\mathrm{Hb}$ concentration improves work output. Although we cannot be certain that work productivity was not affected by some non-Hb factors during the second month, only the initial placebo group showed a raised $\mathrm{Hb}$ concentration and a rise in the mean quantity of tea picked.

The subjects with an initial $\mathrm{Hb}$ concentration of under 9.0 $\mathrm{g} / \mathrm{dl}$ increased their productivity from 15.6 to $17.5 \mathrm{~kg} /$ day $(\mathrm{P}<0.01)$ compared with those initially with concentrations $\geqslant 11.0 \mathrm{~g} / \mathrm{dl}$, whose mean productivity tended to decrease from 16.2 to $16.0 \mathrm{~kg} /$ day. Therefore, the moderately anaemic and iron-deficient subjects once treated were more productive than the normal subjects $(17.5 v 16.0 \mathrm{~kg} /$ day $)$.

The observation that productivity was enhanced by iron treatment seems to be particularly important when the circumstances in which the study was done are considered. For example, every subject was well set into a daily routine that they had followed for six days per week since reaching working age. Furthermore, they worked on the same hills, with the same tea bushes, and with the same people almost without exception. Therefore, they knew what their work productivity was and what was expected of them by their working peers and supervisors. They were also well aware of the amount of tea picked in a given half-day because they carried it in a basket on their back. But despite the constancy of this physical and psychological environment the iron-treated subjects had a higher productivity than the subjects given placebo.

These data represent the first quantitative evidence to our knowledge that the clinical symptoms commonly attributed to iron-deficiency anaemia-namely, tiredness and weakness-may

TABLE II-Mean ( $\pm S E$ of mean) daily productivity (kg of tea picked per subject) in each of the four working divisions before and after iron treatment

\begin{tabular}{|c|c|c|c|c|c|}
\hline \multirow{2}{*}{ Treatment } & \multicolumn{5}{|c|}{ Productivity } \\
\hline & Initially & $\begin{array}{c}\text { After } \\
\text { 1st month }\end{array}$ & $\begin{array}{l}\text { Change in } \\
\text { 1st month }\end{array}$ & $\begin{array}{c}\text { After } \\
\text { 2nd month }\end{array}$ & $\begin{array}{l}\text { Change in } \\
\text { 2nd month }\end{array}$ \\
\hline \multicolumn{6}{|c|}{ Top division } \\
\hline Placebo & $\begin{array}{c}17 \cdot 4 \pm 0 \cdot 3 \\
(n=18)\end{array}$ & $\begin{array}{c}16 \cdot 7 \pm 0.5 \\
(n=18)\end{array}$ & -0.7 & $\begin{array}{c}15.9 \pm 0.5 \\
(n=18)\end{array}$ & $-0.8 \dagger$ \\
\hline Iron & $\begin{array}{c}16.9 \pm 0.6 \\
(n=14)\end{array}$ & $\begin{array}{c}16 \cdot 6 \pm 0 \cdot 6 \\
(n=14)\end{array}$ & $-0.3^{*}$ & $\begin{array}{c}14 \cdot 8 \pm 0 \cdot 4 \\
(n=14)\end{array}$ & $-1 \cdot 8$ \\
\hline Net effect & & & +0.4 & & $+1 \cdot 0$ \\
\hline \multicolumn{6}{|c|}{ Ooragalla division } \\
\hline Placebo & $\begin{array}{c}16 \cdot 1 \pm 0 \cdot 4 \\
(n=46)\end{array}$ & $\begin{array}{c}11 \cdot 8 \pm 0 \cdot 3 \\
(n=46)\end{array}$ & $-4 \cdot 3$ & $\begin{array}{c}9 \cdot 1 \pm 0 \cdot 3 \\
(\mathrm{n}=46)\end{array}$ & $-2 \cdot 7 \dagger$ \\
\hline Iron & $\begin{array}{c}17 \cdot 3 \pm 0.5 \\
(n=28)\end{array}$ & $\begin{array}{r}13 \cdot 1 \pm 0.5 \\
(\mathrm{n}=28)\end{array}$ & $-4 \cdot 2^{*}$ & $\begin{array}{c}10 \cdot 1 \pm 0 \cdot 4 \\
(\mathrm{n}=28)\end{array}$ & $-3 \cdot 0$ \\
\hline Net effect & & & +0.1 & & +0.3 \\
\hline \multicolumn{6}{|c|}{ Middle division } \\
\hline Placebo & $\begin{aligned} & 15 \cdot 9 \pm 0 \cdot 6 \\
&(n=41)\end{aligned}$ & $\begin{array}{l}8 \cdot 3 \pm 0 \cdot 6 \\
(n=41)\end{array}$ & $-7 \cdot 6$ & $\begin{array}{c}7 \cdot 0 \pm 0.6 \\
(n=41)\end{array}$ & $-1 \cdot 3 \dagger$ \\
\hline Iron & $\begin{array}{r}15 \cdot 5 \pm 0.5 \\
(n=46)\end{array}$ & $\begin{array}{c}7 \cdot 9 \pm 0.3 \\
(n=46)\end{array}$ & $-7 \cdot 6^{*}$ & $\begin{array}{c}6 \cdot 7 \pm 0.5 \\
(n=46)\end{array}$ & $-1 \cdot 2$ \\
\hline Net effect & & & 0 & & $-0 \cdot 1$ \\
\hline \multicolumn{6}{|c|}{ Lower division } \\
\hline Placebo & $\begin{array}{r}15 \cdot 0 \pm 0 \cdot 4 \\
(n=34)\end{array}$ & $\begin{array}{l}8 \cdot 8 \pm 0 \cdot 3 \\
(n=34)\end{array}$ & $-6 \cdot 2$ & $\begin{array}{c}6.5 \pm 0.3 \\
(n=34)\end{array}$ & $-2 \cdot 3 \dagger$ \\
\hline Iron & $\begin{array}{c}14.9 \pm 0.9 \\
(n=17)\end{array}$ & $\begin{array}{l}9 \cdot 1 \pm 0 \cdot 7 \\
(n=17)\end{array}$ & $-5 \cdot 8^{*}$ & $\begin{array}{l}6 \cdot 6 \pm 0 \cdot 5 \\
(n=17)\end{array}$ & $-2 \cdot 5$ \\
\hline Net effect & & & +0.4 & & +0.2 \\
\hline Mean net effe & & & +0.2 & & +0.4 \\
\hline
\end{tabular}

Net effects represent effects of iron * after one month compared with placebo and after the second month in subjects in original placebo group compared with those

All four divisions showed a significant effect of iron treatment $(P<0.05)$ compared with the matched placebo group.

exist in man as has been reported for rats. ${ }^{45}$ This is assuming, of course, that when a person feels tired or weak, or both, it is reflected in his level of activity.

The effects of any type of treatment on human voluntary activity are obviously difficult to measure, but we made every effort to eliminate technical and psychological biases. In addition to the care taken in collecting productivity data and matching the time of day, the sensitivity of the activity transducers and any peculiarities that may have existed in any recorder were controlled by assigning them alternately to placebo- and irontreated subjects.

From these results the increased productivity and activity levels cannot be attributed solely to either $\mathrm{Hb}$ concentration or other factors. Iron treatment appears to have a bradycardia effect that is unrelated to $\mathrm{Hb}^{6}{ }^{6} 7$ For example, within four days after iron treatment was begun the heart-rate response to a given intensity of exercise was lower than expected for a given $\mathrm{Hb}$ concentration. This same effect could have been a factor 
responsible for the observations that the heart rate for a given level of physical activity was lower in the iron-treated than placebo-treated subjects.

The economic implications of increased work productivity with iron treatment are evident, particularly in developing countries. These results also provide strong evidence for the clinical notion that subjects with iron-deficiency anaemia are characterised by tiredness and weakness. We do not know whether this effect is related to iron deficiency or to the degree of anaemia that might be critical for a change in voluntary activity to occur as a result of iron treatment.

This study was supported by J B Williams Co, New York. We also acknowledge the co-operation of the staff in the clinical research unit (Nuffield Foundation), Kandy General Hospital, Sri Lanka, especially Miss H Perera and Mr G A Senewiratne. We are indebted to Ms A
Gardner, Ms $M$ Edgerton, $M r$ Ratwatte, and $\mathrm{Mr}$ Shadrack, staff of the Oodawella Estate, for their help in the field; and to Ms K B Hartman and Ms J D Moss for their help in the data"analysis.

\section{References}

${ }^{1}$ Basta, S S, and Churchill, A, World Bank Staff, Working Paper, No 175. Washington, DC, World Bank, 1974

${ }^{2}$ Popkin, B M, et al, report submitted to Department of Public Works, Philippines, February, 1975.

${ }^{3}$ Viteri, F E, et al, American fournal of Clinical Nutrition, 1971, 24, 1418

4 Glover, J, and Jacobs, A, British Medical fournal, 1972, 2, 627.

${ }^{5}$ Edgerton, V R, et al, Fournal of Nutrition, 1977, 107, 1595.

${ }^{6}$ Ohira, Y, et al, Nutrition Reports International, 1978, 18, 647.

${ }^{7}$ Ohira, Y, et al, British fournal of Haematology, 1979, 41, 365.

\title{
Pruritus ani: is anal sphincter dysfunction important in aetiology?
}

\author{
ANTHONY A EYERS, JAMES P S THOMSON
}

British Medical fournal, 1979, 2, 1549-1551

\section{Summary and conclusions}

Forty-three patients whose principal symptom was pruritus ani were studied. Twenty-eight had anal disease, while in 15 no such disease could be shown. Maximum resting pressures and transient and sustained pressures of the anal canal in response to rectal distension were measured by manometry. Although the maximum resting pressure in the patients with no disease was about the same as that in the group with disease, the pressures recorded in response to rectal distension were significantly lower.

These results show that the anal sphincter relaxes in response to rectal distension more readily in patients with no anal disease. Hence soiling may occur, which may be a factor in the genesis of pruritus ani.

\section{Introduction}

Pruritus ani is a troublesome symptom that is associated with most forms of anal disease, but in some patients with this symptom no aetiological anal disease may be found. As soiling is a frequent feature in the history of these patients, even in those without anal disease, we decided to assess the anal sphincter function by manometry ${ }^{1-3}$ in a group of patients in whom pruritus ani was the major presenting symptom.

\section{Patients and methods}

Between October 1978 and March 1979, 49 patients whose principal symptom was pruritus ani were seen at three of this hospital's six regular outpatient clinics. Six patients were excluded from the study: four refused manometry, and two had previously undergone internal sphincterotomy. Table I shows the age and sex distribution of the 43 patients studied. Six normal young male volunteers were also studied.

TABLE I-Age distribution of patients studied (mean age $44 \cdot 2$ (range 20-72) years)

\begin{tabular}{|c|c|c|c|c|c|c|c|}
\hline & Age (years): & $20-29$ & $30-39$ & $40-49$ & $50-59$ & $60-69$ & $70-79$ \\
\hline $\begin{array}{l}\text { Men } \\
\text { Women }\end{array}$ & $\because$. & 4 & 11 & $\begin{array}{r}10 \\
5\end{array}$ & $\begin{array}{l}7 \\
2\end{array}$ & $\begin{array}{l}2 \\
1\end{array}$ & 1 \\
\hline
\end{tabular}

\section{CLINICAL METHODS}

In taking a careful history from each patient particular note was made of whether the patient (1) frequently experienced minor degrees of soiling of his underwear with faeces at times other than when this might be explained by rubbing or scratching the area, and (2) had a generalised chronic or recurring rash. In performing an anorectal examination (comprising inspection, palpation, proctoscopy, and sigmoidoscopy) particular note was made of (1) the severity of the local changes in pruritus, graded on an arbitrary scale $(1=$ no changes, $4=$ pronounced changes); and (2) the presence or absence of any anal disease to which the pruritus might be attributed. In the group studied this included haemorrhoids, fissure in ano, anal-canal polyps, and anal skin tags. All examinations were performed by two clinicians, one of whom was always AAE.

The height and weight of each patient were measured.

\section{MYCOLOGICAL CULTURES}

Perianal skin scrapings were taken from each patient, and a record was kept of any growth of Candida albicans or filamentous fungus within six weeks after inoculation on to appropriate culture plates.

\section{ANAL-CANAL MANOMETRY}

Patients attended one to three weeks after the initial assessment for anal manometry. This procedure was performed in each case by the same clinician, who used a routine technique, and without specific reference to the records made at the first visit. 